\title{
Autour d'un film : « Les Servantes du Bon Dieu »
}

\section{Pierre Hurtubise}

Volume 46, 1979

URI : https://id.erudit.org/iderudit/1007115ar

DOI : https://doi.org/10.7202/1007115ar

Aller au sommaire du numéro

Éditeur(s)

Les Éditions Historia Ecclesiæ Catholicæ Canadensis Inc.

ISSN

0318-6172 (imprimé)

1927-7067 (numérique)

Découvrir la revue

Citer cet article

Hurtubise, P. (1979). Autour d'un film : « Les Servantes du Bon Dieu ». Sessions d'étude - Société canadienne d'histoire de l'Église catholique, 46, 61-63.

https://doi.org/10.7202/1007115ar

Tous droits réservés @ Les Éditions Historia Ecclesiæ Catholicæ Canadensis Inc., 1979
Ce document est protégé par la loi sur le droit d'auteur. L'utilisation des services d'Érudit (y compris la reproduction) est assujettie à sa politique d'utilisation que vous pouvez consulter en ligne.

https://apropos.erudit.org/fr/usagers/politique-dutilisation/ 


\section{Autour d'un film : "Les Servantes du Bon Dieu »}

Pour la première fois dans son histoire, la S.C.H.E.C. inscrivait au programme d'un de ses congrès, en plus des sept ou huit communications habituelles, une production cinématographique, en l'occurrence le film bien connu de Diane Létourneau : Les Servantes du Bon Dieu. Ce documentaire portant sur les Petites Sœurs de la Sainte-Famille, communauté d'auxiliaires du clergé dont la maison généralice est présentement à Sherbrooke, fut présenté à un public nombreux et intéressé le vendredi 14 septembre, à 20 heures, premier jour du Congrès.

Nous avions pensé inviter la réalisatrice à venir présenter et commenter elle-même son œuvre, mais n'ayant pu le faire, nous avons tout de même pu mettre à la disposition du public un certain nombre de coupures de presse portant sur le film et sur les réactions qu'il a suscitées dans le public en général et chez les critiques en particulier. Pourquoi cette première dans l'histoire de nos congrès? Parce que nous croyions le moment venu de signaler l'importance grandissante du document audio-visuel comme source, mais également comme œuvre d'histoire.

Le film de Diane Létourneau est, de fait, l'une et l'autre. Il se présente comme un constat, c'est-à-dire, comme elle le suggère ellemême, «un portrait sur la quotidienneté de ces femmes, en les respectant, en essayant de les accepter telles qu'elles sont et dans la manière dont elles vivent et dont elles pensent », mais il ne peut d'autre part éviter d'être un commentaire, serein et discret il faut le dire, mais commentaire tout de même, sur la situation de la religion et de la femme telle qu'elle se présentait au Québec il y a à peine une ou deux générations. À ce double titre, il s'agit bien d'un document d'histoire et d'un type de document dont les historiens seront de plus en plus forcés de tenir compte. 
Il est intéressant de noter qu'en entreprenant Les Servantes $d u$ Bon Dieu, Diane Létourneau avait déjà en tête deux autres volets, l'un consacré aux "mères du temps des grosses familles", l'autre aux "vieilles filles", en somme aux trois vocations (avec celle des religieuses) traditionnellement réservées aux femmes québécoises jusqu'au début des années 60 . Si elle a finalement décidé de se limiter aux seules religieuses et, parmi celles-ci, à la seule communauté des Petites Sœurs de la Sainte-Famille, c'est que, d'une part, elle se rendait compte de la démesure de son projet initial et que, d'autre part, elle avait trouvé dans les communautés d'auxiliaires du clergé et plus particulièrement dans celle des Petites Sœurs de la Sainte-Famille, un modèle répondant parfaitement à son propos, c'est-à-dire, comme elle le souligne elle-même, n'ayant "presque pas bougé depuis la révolution tranquille». Car l'intention première et profonde de son film c'était, comme elle le reconnaît elle-même, de s'approprier et de faire revivre un passé qu'on croyait définitivement relégué aux oubliettes. "Depuis les années 60 , explique-t-elle, on a totalement rejeté tout ce qui concerne la religion, et à commencer par les communautés religieuses. Les sœurs, on les a sorties des hôpitaux, on les a sorties des écoles, pour réellement les précipiter dans l'ombre, du jour au lendemain. J'en sais quelque chose puisque je fais partie de cette génération-là, et je me rends compte que dans 10 ans on n'aura plus rien sur notre réalité québécoise de cette époque qui a été pourtant très importante. Et ne serait-ce que pour cette simple raison, je pense que mon film peut devenir un document important au Québec et ailleurs aussi ».

Les critiques sont unanimes à souligner l' «objectivité » et la maturité du regard porté par la réalisatrice sur la réalité qu'elle a choisi de décrire. Par contre, ils signalent tous également la réaction assez peu "objective » et souvent passionnée que le film suscite chez les spectateurs. Témoins d'un passé que certains regrettent, d'autres condamnent, d'autres encore trouvent insolite ou incompréhensible, les Petites Sœurs projettent une image, simple et dérangeante tout à la fois, qui ne laisse personne indifférent. Le film de Diane Létourneau agit, en quelque sorte, comme un Rorschach, un Rorschach, il faut l'avouer, d'une rare efficacité. "C'est sûrement, écrit Josée Beaudet. la plus grande qualité du film, par ailleurs très beau et techniquement très bien fait, de nous intéresser pendant quatre-vingt-dix minutes, quels que soient nos préjugés de départ, sans jamais tricher avec la caméra ou le montage ». À quoi faire? « $\grave{A}$ regarder vivre des Martiennes, diront les uns, des pauvres exploitées, diront les autres, 
peut-être même des folles, des exaltées, en tout cas des femmes sympathiques, devant qui on demeure perplexe, ne pouvant nier ni leur intelligence, ni leur complète aliénation, ni leur bonheur».

Il y avait surtout de la sympathie et assez peu de perplexité parmi l'auditoire devant lequel nous avons projeté Les Servantes $d u$ Bon Dieu le vendredi, 14 septembre 1979, à Gaspé, mais les réactions que nous avons pu recueillir, le soir même ou le lendemain, n'en étaient pas moins très diversifiées et très partagées, confirmant par là le caractère très «subjectif » de la lecture qu'en font habituellement les auditoires devant lesquels il est projeté. Et cela aussi pourrait éventuellement intéresser l'historien.

Pierre Hurtubise, o.m.i.,

Centre de recherche en

histoire religieuse,

Université Saint-Paul,

Ottawa. 